\title{
O ENSINO DE SAÚDE PÚBLICA NAS ESCOLAS DE MEDICINA VETERINÁRIA: AS INSTITUIÇÕES PÚBLICAS COMO ESPELHO PARA AS PARTICULARES.
}

\author{
PUBLIC HEALTH EDUCATION IN VETERINARY SCHOOLS: PUBLIC \\ INSTITUTIONS AS A MIRROR TO PRIVATE INSTITUTIONS
}

\author{
C. A. CRUZ ${ }^{2}$, E. M. N. PAULA ${ }^{1}$, C. S. L. NOGUEIRA ${ }^{2}$, M. B. DELAMONICA, R. B. MEIRELLES- \\ BARTOLI ${ }^{1}$, K. P. BÜRGER, L. A. MATHIAS
}

\section{RESUMO}

A demanda por Médicos Veterinários envolvidos em saúde pública e na estratégia "Um mundo uma saúde" vem aumentando no Brasil e no mundo, surgindo a preocupação com a formação acadêmica nessa área. Uma vez que o número de instituições privadas de ensino superior em Medicina Veterinária aumenta a cada ano no Brasil, o presente trabalho teve como objetivo verificar se a carga horária dedicada a essas de Saúde Pública disciplinas favorece o egresso para atuação na área, além de comparar estatisticamente a carga horária em saúde pública das matrizes curriculares de instituições de ensino superior (IESs) públicas e particulares da região sudeste do Brasil. Foi utilizada pesquisa documental tomando como fonte as matrizes curriculares utilizadas nos cursos de graduação em Medicina Veterinária das IESs. Para a análise estatística foi utilizado software $\mathrm{R}$ e foi feita análise de variância para verificar influências do Estado e do tipo de administração da carga horária. A partir da análise de 87 matrizes curriculares, nota-se que a média de carga horária dedicada à saúde pública é de apenas 239,54 horas contra 1.182, 76 horas para a clínica veterinária, por exemplo. Por meio da análise de variância entendese que não há efeito de tratamento; portanto, não há efeito dos fatores nem há interação. Ao se analisar o resíduo não há normalidade a $5 \%(\mathrm{P}<0,05)$, mas há normalidade a $1 \%(\mathrm{P}>0,01)$. Portanto as matrizes não contemplam de forma adequada a área de atuação da Saúde Pública Veterinária, preconizando ainda a formação individual e curativa. Além disso observa-se que não há diferença entre as cargas horárias dedicadas à Saúde Pública em relação à categoria administrativa para nenhuma disciplina e nem para nenhum Estado, demonstrando-se que o ensino privado se espelha no ensino público, dedicando-se à área de Saúde Pública da mesma maneira.

PALAVRAS-CHAVE: EGRESSO, FORMAÇÃO, MATRIZ CURRICULAR, SAÚDE PÚBLICA.

\section{ÁREA TEMÁTICA:}

\footnotetext{
${ }^{1}$ Universidade Federal de Goiás (UFG), Regional Jataí, Unidade Jatobá, Laboratório de Sanidade Animal

${ }^{2}$ Faculdade de Ciências Agrárias e Veterinárias da Universidade Estadual Paulista (UNESP) - Câmpus de Jaboticabal

* carol_a_cruz@yahoo.com.br
} 